\title{
Physical and chemical cues affect oviposition by Neoleucinodes elegantalis
}

\author{
WENDEL J. TELES PONTES ${ }^{1}$, ERALDO RODRIGUES LIMA², \\ ERIVELTON G. CUNHA ${ }^{2}$, PEDRO M. TEIXEIRA DE ANDRADE ${ }^{2}$, \\ A I L T O N PINHEIR O L ÔB O ${ }^{1}$ and RE G INAL D O B ARR O S \\ ${ }^{1}$ Laboratory of Insect Behavior, Departamento de Agronomia, Universidade Federal Rural de Pernambuco, Recife, Brazil and \\ ${ }^{2}$ Laboratory of Semiochemicals and Insect Behavior, Departamento de Biologia Animal, Universidade Federal de Viçosa, \\ Viçosa, Brazil
}

\begin{abstract}
Recognition and acceptance of a suitable host plant by phytophagous insects requires the integration of visual, physical and chemical cues. The present study investigates the host cues that a specialist insect integrates to optimize oviposition decisions and whether these cues are weighted in a specific way. The study also determines whether the tomato fruit borer Neoleucinodes elegantalis (Guenée) (Lepidoptera: Crambidae), an important pest on Solanaceae in Brazil, shows a preference for oviposition sites that differ in physical and/or chemical cues. When styrofoam balls are provided as artificial fruits, $N$. elegantalis deposit significantly more eggs on rough artificial fruits than on smooth ones. Hexane fruit extracts applied to the artificial fruits stimulate female oviposition strongly. Physical and chemical cues also affect the oviposition of females when offered together. Furthermore, certain parts of the artificial fruits are prefered, irrespective of the presence of chemical cues. Both physical and chemical cues affect oviposition decisions; hence, the fruit borer relies on cues of different sensory modalities.
\end{abstract}

Key words. Artificial fruits, chemical stimuli, egg-laying behaviour, physical stimuli, tomato fruit borer.

\section{Introduction}

Finding a suitable host plant is one of the critical steps for reproduction of all phytophagous insects (Thompson \& Pellmyr, 1991). Because newly-hatched larvae are relatively immobile, they are unable to find a better host when their mother has oviposited on a host that is unsuitable for larval development (Renwick \& Chew, 1994).

Recognition of a suitable host plant requires integration of inputs from physical and chemical senses. Olfaction and vision may be used for long-distance orientation to the host plant. After landing, short-distance judgment requires senses to detect chemical and physical cues, using contact chemoreceptors on antennae, mouthparts and ovipositors. Usually, recognition of

Correspondence: Wendel J. Teles Pontes, Pós-Graduação em Entomologia Agrícola, Departamento de Agronomia, Universidade Federal Rural de Pernambuco, Rua Dom Manoel de Medeiros, s/n, Dois Irmãos, Recife/PE, CEP 52171-900, Brazil. Tel.: +55 81 33206215; e-mail: pontes.wendel@gmail.com chemical compounds on the plant surface results in a decision to accept or reject the oviposition site (Ramaswamy, 1988; Renwick \& Chew, 1994).

Physical characteristics of the oviposition site such as surface texture play a critical role in the final decision to lay eggs (Renwick \& Chew, 1994). Some moths prefer to oviposit on hairy or rough surfaces (Ramaswamy, 1988; Rojas et al., 2003; Nava et al., 2005), whereas other species prefer smooth surfaces (Foster et al., 1997; Calatayud et al., 2008).

Chemical compounds present on plant surfaces can be volatiles that contribute toward long-distance orientation to the host plant, or nonvolatile compounds that play a role as oviposition stimulants or deterrents (Renwick \& Chew, 1994). It is well established that these chemical cues are very important with respect to the orientation and acceptance of oviposition sites in several species of Lepidoptera (Ramaswamy, 1988; McNeil \& Delisle, 1989; Honda, 1995; Peterson \& Elsey, 1995; Hora \& Roessingh, 1999; Reddy et al., 2004; Gouinguené et al., 2005; Lombarkia \& Derridj, 2008; Sidney et al., 2008).

(C) 2010 The Authors Journal compilation (c) 2010 The Royal Entomological Society 
For both physical and chemical cues, preferences among phytophagous insects depend on host suitability because host plants differ in the physical and chemical cues that insects use to discriminate between hosts. Oligophagous insects might concentrate on one or a few cues that are specific to their host plant, and have a high ability to evaluate these cues and discriminate between oviposition sites (Janz \& Nylin, 1997). The recognition of these cues depends on the insect sensory system for detecting and decoding the signals available in the host (Dethier, 1982). However, the rejection and acceptance of oviposition sites depends on the analysis of sensory input by the insect's central nervous system and the physiological state of the insect.

The tomato fruit borer Neoleucinodes elegantalis (Guenée) (Lepidoptera: Crambidae) is an important oligophagous pest on Solanaceae. Adults are active at night only. First-instar larvae have low mobility and bore inside the fruits within a few minutes of hatching (Eiras \& Blackmer, 2003). When the fruits are unavailable, larvae are moribund (W. Pontes, unpublished data). This suggests that mated females are under a strong selection pressure to find the correct site to lay eggs. Hence, mated females should have the ability to detect cues indicating hosts and host quality. Neoleucinodes elegantalis also shows a preference for laying eggs on specific places of fruits (i.e. under the calix) (Blackmer et al., 2001). However, it is not known what kind of physical and chemical cues determine oviposition choice by $N$. elegantalis, or whether they are sensitive to luminescence as members of the closest family Pyralidae appear to be (Briscoe \& Chittka, 2001). The present study therefore tests which physical cues (i.e. surface types) and which chemical cues affect oviposition in N. elegantalis females, and how these cues of different sensory modality interact.

\section{Materials and methods}

Neoleucinodes elegantalis were collected from a commercial tomato crop in Minas Gerais State, Brazil, and reared in the laboratory for 2 years. Both the rearing and experimental conditions were performed under an LD $12: 12 \mathrm{~h}$ photocycle at $25 \pm 1{ }^{\circ} \mathrm{C}$ and $71.2 \pm 10 \%$ relative humidity. The larvae were reared on Solanum gilo (Solanaceae) fruits until pupation. Pupae were sexed and each gender was incubated in separate experimental wooden cages $(50 \times 50 \times 50 \mathrm{~cm})$. On emergence, males and females were kept together during 3 days for copulation in another cage with a cotton piece soaked in a honey solution (10\%). After approximately 3 days, the females were used in the experiments, and thereafter dissected to assess the presence of spermatophores in the bursa copulatrix (Burns, 1968). To assess oviposition, Styrofoam ${ }^{\circledR}$ balls (diameter $3.5 \mathrm{~cm}$ ) were used as artificial fruits. All of the balls were dipped in green melted paraffin to produce a thin wax layer that covered the surface. Nine replicates were studied for each treatment in each experiment, and each replicate involved the oviposition response of a group of ten females.

\section{Physical cues}

To test the influence of physical cues on $N$. elegantalis, ovipositing females were offered a choice between two different surfaces. Ten 48-h-old gravid females were used. Longitudinal furrows were made with a razor blade on the surface of the artificial fruits to obtain a rough surface. Intact artificial fruits were considered as smooth. A rough and a smooth artificial fruit were suspended, approximately $25 \mathrm{~cm}$ apart, from the top of the cage using wire. Between replicates, and after $24 \mathrm{~h}$ within one experiment, the positions of the artificial fruits were interchanged to avoid environmental bias. The females were allowed to oviposit for $48 \mathrm{~h}$. Thereafter, eggs on each artificial fruits were counted. On rough artificial fruits, eggs on the smooth surface and in the furrows were counted separately.

\section{Chemical cues}

Tomatoes fruits, Lycopersicon esculentum L. (Solanaceae, variety Sensação, Agrocinco, São Paulo), with a diameter of approximately $1.5 \mathrm{~cm}$, were collected in a commercial tomato crop in Minas Gerais State, Brazil, for the extraction of chemical cues. The fruits were weighed and immersed in hexane for $30 \mathrm{~min}$. Subsequently, the solution was reduced to dryness by evaporation of the solvent. The fruit extract was then expressed as gram fruit equivalent per millilitre solvent and kept in a freezer $\left(-18{ }^{\circ} \mathrm{C}\right)$ until used in the tests.

To determine whether these fruit extracts affected the oviposition decision of females, a choice test was performed with artificial fruits containing extracts and controls without extract. The fruit extract was applied on a 5-mm wide strip of filter paper, which was wrapped horizontally around the artificial fruit, like a ring, and glued on the ends. For each treatment, $30 \mu \mathrm{L}$ of the hexane extract was applied to the filter paper; the same amount of pure hexane was applied to the controls. Groups of ten gravid females were offered a choice between these two artificial fruits for $24 \mathrm{~h}$, after which the number eggs on each artificial fruit was counted. The number of eggs deposited on the waxy surface on the upper face of the strip of paper, and also under the strip of paper, were counted separately and compared between treatments.

\section{Visual and chemical cues}

To evaluate the effect of chemical and visual cues on oviposition, four treatments were offered to females: both chemical and visual cues; only visual cues; only chemical cues; and neither of the two cues.

To manipulate visual cues, experimental cages were placed under low light intensity ( 0.11 lux, measured with a luxometer) providing the minimum light intensity for insect activity and used to rear $N$. elegantalis during the scotophase. The absence of visual cues was mimicked by placing cages in absolute darkness. Chemical cues were offered on smooth artificial fruits to which a hexane extract of tomato fruits was applied, 
as described above. Females were allowed to oviposit for $48 \mathrm{~h}$. In this experiment, all treatments were repeated five times with six females per replicate. Eggs were counted after $24 \mathrm{~h}$.

\section{Statistical analysis}

A chi-square test was employed to analyse the choice between each treatment in both the physical and chemical tests. The mean percentage of eggs on each of the two artificial fruits was calculated.

To test the combined effects of visual and chemical cues on oviposition of females, eggs were counted on each artificial fruit in all treatments and analyzed with generalized linear model with a quasi-poisson error distribution. All analyses were performed with $\mathrm{R}$ statistical system, version 2.4.1. (R Development Core Team, 2006).

\section{Results}

\section{Physical cues}

Neoleucinodes elegantalis deposited significantly more eggs on rough artificial fruits than on smooth ones $\left(\chi^{2}=22.65\right.$, $P<0.0001$ ) (Fig. 1A). More eggs on rough artificial fruits were found inside the furrows $\left(\chi^{2}=51.12, P<0.0001\right)$ than on the waxy smooth surface (Fig. 1A).

\section{Chemical cues}

More eggs were found in treatments with hexane extracts than in the control $\left(\chi^{2}=3.92, P=0.0475\right)$ (Fig. 1B). More eggs were laid on the filter paper strips with hexane extracts than on strips with only hexane $\left(\chi^{2}=8.20, P=0.0041\right)$ (Fig. 2A) and more eggs were laid on the wax layer of the
A

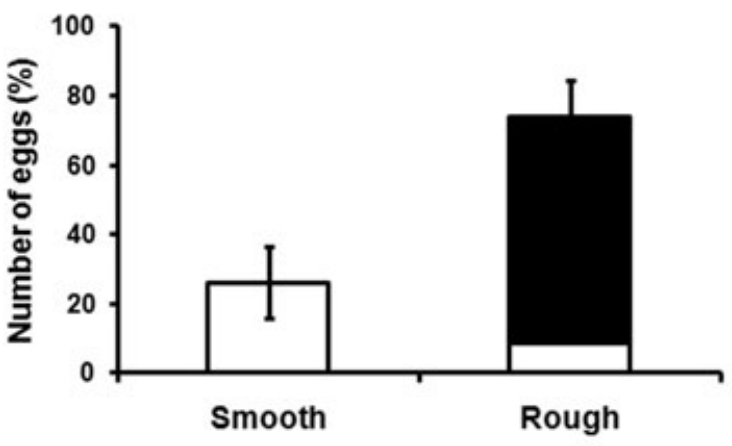

B

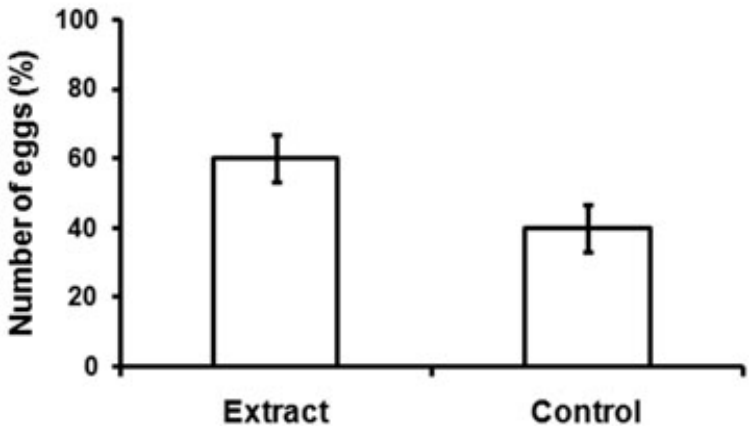

Fig. 1. (A) Mean percent of eggs of Neoleucinodes elegantalis deposited on smooth and rough artificial fruits when they were offered simultaneously in a two-choice test. The right bar shows the amount of eggs layed inside furrows (black) on rough artificial fruits. (B) Eggs deposited on artificial fruits treated with hexane extracts of tomato fruits compared with artificial fruits treated with hexane only (control). Error bars indicate standard errors.

artificial fruit with tomato hexane extracts than on that with hexane only $\left(\chi^{2}=8.26, P=0.0040\right)$ (Fig. $\left.2 B\right)$. Similarly, more eggs were deposited under of the filter paper strip on the
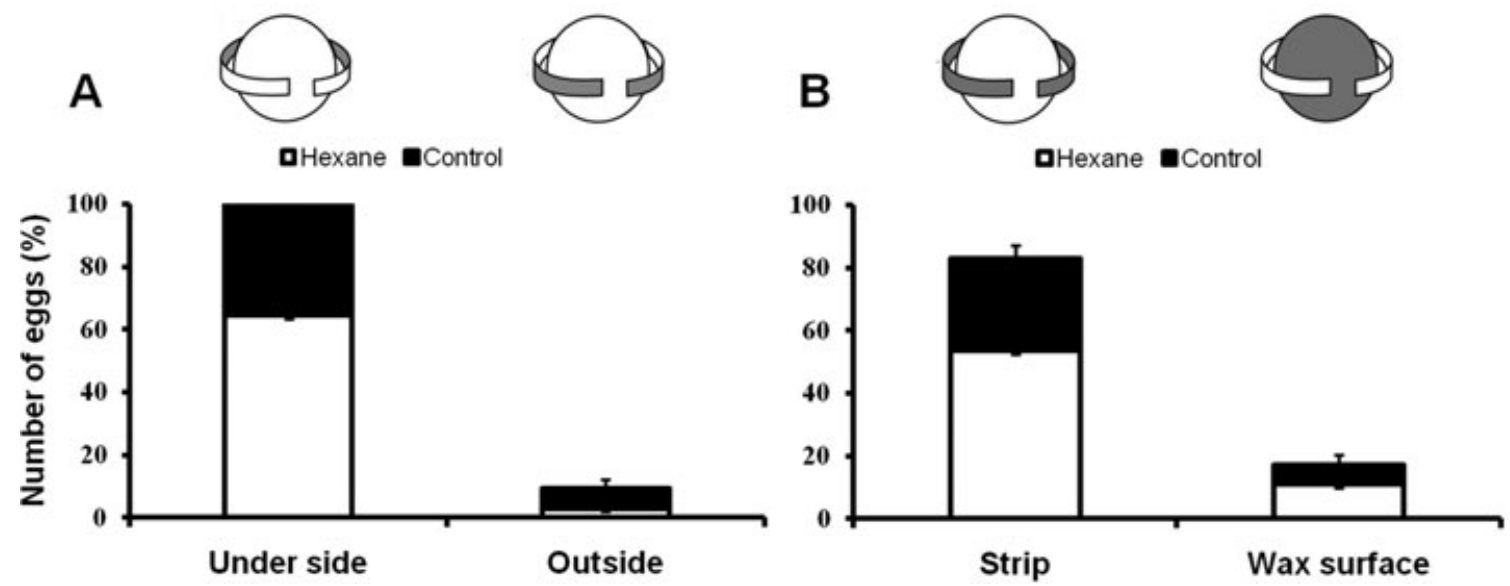

Fig. 2. Number of eggs deposited by Neoleucinodes elegantalis on artificial fruits with hexane extract (open bars) and only hexane (black bars). (A) Eggs underside of the strip and the strip (outside) and (B) eggs on the whole strip and the wax surface. Egg deposition areas are highlighted in grey. 


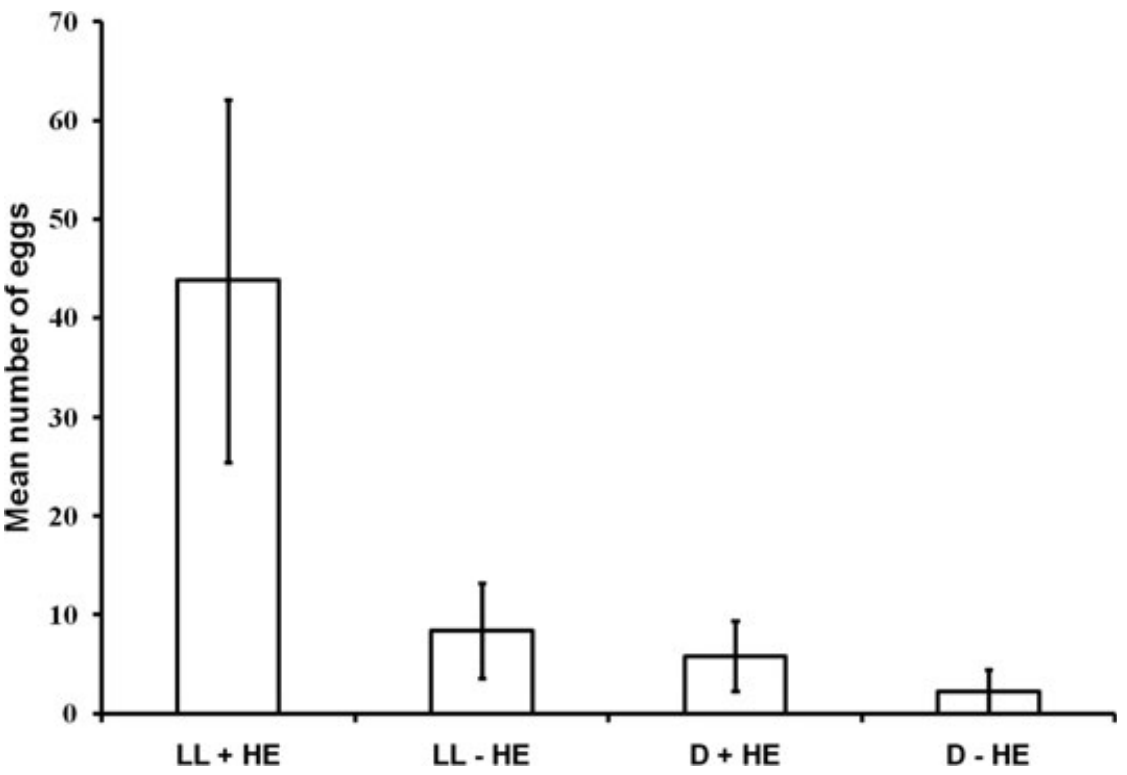

Fig. 3. Mean number of Neoleucinodes elegantalis eggs on artificial fruits in visual and chemical conditions (LL, low light intensity; HE, hexane extract; D, absolute darkness). Only the values recorded for the LL + HE treatment are significantly different from the others. Error bars indicate standard errors.

artificial fruits treated with tomato hexane extracts $\left(\chi^{2}=8.27\right.$, $P=0.0040)$ than under the strip on the artificial fruits treated with solvent only (Fig. 2A, B). Most of the eggs were laid under the paper strip, followed by eggs on the strips, and in smaller quantities on the wax layer of the artificial fruits. This pattern was observed both in treatments (i.e. with hexane extracts and with hexane as control) (Fig. 2A, B).

\section{Visual and chemical cues}

Significantly more eggs were laid when both visual and chemical cues were available at the same time $\left(\chi^{2}=321.3\right.$, $P<0.0001$, d.f. $=3$ ) (Fig. 3). However, no differences in egg number were found when at least one of the cues (or both of them) was removed.

\section{Discussion}

The results of the present study show that physical and chemical cues affect the oviposition of $N$. elegantalis. The effect of physical factors on oviposition in Lepidoptera is well known. Some species prefer smooth surfaces (Foster et al., 1997; Calatayud et al., 2008), whereas other species prefer rough substrates (Ramaswamy, 1988; Rojas et al., 2003; Nava et al., 2005). A preference for smooth surfaces may help the females to sweep their ovipositor over the surface to taste and thereby find a suitable site for oviposition (Calatayud et al., 2008). However, a preference for rough surfaces (Ramaswamy, 1988; Fenemore, 1988) appears to be more general (Rojas et al., 2003).
The large number of eggs found inside the furrows of roughened artificial fruits suggests a preference to oviposit in places that are less exposed to environmental conditions and natural enemies (Janz, 2002). For example, in Pieris rapae crucivora, not only surface texture is preferred for egg laying, but also plant parts are preferred that can provide some protection to eggs (Tagawa et al., 2008).

The oviposition behaviour of $N$. elegantalis is observed in some cases: females walk on the surface, thereby contacting the surface of the artificial fruit with their antennae and the tip of the proboscis and dragging the ovipositor over the substrate when walking (W. Pontes, unpublished data). This behaviour suggests that sensory organs for tactile and chemical cues are located on the antennae, proboscis and ovipositor. Many butterflies and moths are known to antennate and drum the plant surface with their ovipositor prior to egg laying, and thus probably are using contact chemoreceptors to taste the suitability of chemical compounds and to explore the surface texture of their host plant (Visser, 1986; Renwick \& Chew, 1994; Maher \& Thiery, 2004). The antennal receptors of other Lepidoptera species show differential sensitivity to host and nonhost plants (Mercader et al., 2008).

Hexane extracts of fruits stimulate oviposition by N. elegantalis significantly. All artificial fruits on which tomato extracts are applied are preferred for oviposition. The application of host plant chemical compounds to artificial substrates makes these sites usually more acceptable for oviposition (Foster \& Howard, 1998; Hora \& Roessingh, 1999; Heinz \& Feeny, 2005; Heinz, 2008).

The fact that a hexane extract of tomato stimulates oviposition in $N$. elegantalis does not rule out the influence of visual cues on oviposition behaviour; light is required to locate a source of attractive chemicals. Most females lay more 
eggs in experimental cages when both cues (in this case, visual and chemical) are available. The few eggs that are found on artificial fruits in absolute darkness and without extract (no chemical cue) are perhaps the result of some females that randomly encounter the artificial fruits, land on it, and oviposit.

More eggs are laid when chemical stimuli are combined with rough surfaces; when a filter paper treated with extracts is combined with the artificial fruit, the rough surface of the filter paper receives the highest humber of eggs. This shows an interaction of chemical and physical cues on oviposition decisions. Volatiles and nonvolatile compounds are known to stimulate attraction of gravid females (Piñero \& Dorn, 2007) and to increase the number of eggs layed on the source (Honda, 1995; Spencer et al., 1999). The present study shows that $N$. elegantalis females also use different sensory modalities to assess oviposition sites.

In both treatments, with and without hexane extract, the insects prefer to lay eggs under the strip, near the edge, which is probably similar to their preference to lay eggs in a furrow. In the field, eggs of $N$. elegantalis are found mainly on the underside of the calyx, and this preference is suggested to be a result of physical rather than chemical cues (Blackmer et al., 2001). In the present study, $N$. elegantalis prefer furrow-like places on the artificial fruits, irrespective of whether they are offered chemical stimulants or not. However, the presence of hexane extracts increases the total number of eggs laid by females significantly, in a combined effect of physical and chemical stimuli presented together.

\section{Acknowledgements}

We thank Maurice W. Sabelis and Izabela Lesna for their valuable comments on the manuscript; J. D. Matiello and S.A.S. Souza for assistance with the experiments and their analysis. This research was supported by CNPq-INCT Semiochemicals in Agriculture, PROCAD/CAPES 0083054; and a CNPq scholarship to E.R.L., E.G.C., P.M.T.A. and R.B.

\section{References}

Blackmer, J., Eiras, A. \& Souza, C. (2001) Oviposition preference of Neoleucinodes elegantalis (Guenée) (Lepidoptera: Crambidae) and rates of parasitism by Trichogramma pretiosum Riley (Hymenoptera: Trichogrammatidae) on Lycopersicon esculentum in São José de Ubá, RJ, Brazil. Neotropical Entomology, 30, 89-95.

Briscoe, A.D. \& Chittka, L. (2001) The evolution of color vision in insects. Annual Review of Entomology, 46, 471-510.

Burns, J. (1968) Mating frequency in natural populations of skippers and butterflies as determined by spermatophore counts. Zoology, 61, 852-859.

Calatayud, P., Ahuya, P., Wanjoya, A. et al. (2008) Importance of plant physical cues in host acceptance for oviposition by Busseola fusca. Entomologia Experimentalis et Applicata, 126, 233-243.

Dethier, V.G. (1982) Mechanism of host-plant recognition. Entomologia Experientalis et Applicata, 31, 46-56.
Eiras, A. \& Blackmer, J. (2003) Eclosion time and larval behavior of the tomato fruit borer, Neoleucinodes elegantalis (Guenée) (Lepidoptera: Crambidae). Scientia Agricola, 60, 195-197.

Fenemore, P. (1988) Host-plant location and selection by adult potato moth, Phthorimaea operculella (Lepidoptera: Gelechiidae): a review. Journal of Insect Physiology, 34, 175-177.

Foster, S. \& Howard, A. (1998) Influence of stimuli from Camellia japonica on ovipositional behavior of generalist herbivore Epiphyas postvittana. Journal of Chemical Ecology, 24, 1251-1275.

Foster, S., Howard, A. \& Harris, M. (1997) The influence of tactile and other non-chemical factors on the ovipositional responses of the generalist herbivore Epiphyas postvittana. Entomologia Experimentalis et Applicata, 83, 147-159.

Gouinguené, S., Buser, H.-R. \& Städler, E. (2005) Host-plant leaf surface compounds influencing oviposition in Delia antiqua. Chemoecology, 15, 243-249.

Heinz, C. (2008) Host plant odor extracts with strong effects on oviposition behavior in Papilio polyxenes. Entomologia Experimentalis et Applicata, 128, 265-273.

Heinz, C. \& Feeny, P. (2005) Effects of contact chemistry and host plant experience in the oviposition behaviour of the eastern black swallowtail butterfly. Animal Behaviour, 69, 107-115.

Honda, K. (1995) Chemical basis of differential oviposition by lepidopterous insects. Archives of Insect Biochemistry and Physiology, 30, 1-23.

Hora, K. \& Roessingh, P. (1999) Oviposition in Yponomeuta cagnagellus: the importance of contact cues for host plant acceptance. Physiological Entomology, 24, 109-120.

Janz, N. (2002) Evolutionary ecology of oviposition strategies. Chemoecology of Insect Eggs and Egg Deposition (ed. by M. Hilker and T. Meiners), pp. 349-376. Wiley-Blackwell, Germany.

Janz, N. \& Nylin, S. (1997) The role of female search behaviour in determining host plant range in plant feeding insects: a test of the information processing hypothesis. Proceedings of the Royal Society of London Series B, Biological Sciences, 264, 701-707.

Lombarkia, N. \& Derridj, S. (2008) Resistance of apple trees to Cydia pomonella egg laying due to leaf surface metabolites. Entomologia Experimentalis et Applicata, 128, 57-65.

Maher, N. \& Thiery, D. (2004) Distribution of chemo- and mechanoreceptors on the tarsi and ovipositor of female european grapevine moth, Lobesia botrana. Entomologia Experimentalis et Applicata, 110, 135-143.

McNeil, J. \& Delisle, J. (1989) Host plant pollen influences calling behavior and ovarian development of the sunflower moth, Homoeosoma electellum. Oecologia, 80, 201-205.

Mercader, R., Stelinski, L. \& Scriber, J. (2008) Differential antennal sensitivities of the generalist butterflies Papilio glaucus and $P$. canadensis to host plant and non-host plant extracts. Journal of the Lepidopterists' Society, 62, 84-88.

Nava, D., Parra, J., Diez-Rodríguez, G. \& Bento, J. (2005) Oviposition behavior of Stenoma catenifer (Lepidoptera: Elachistidae): chemical and physical stimuli and diet pattern of egg laying. Annals of the Entomological Society of America, 98, 409-414.

Peterson, J. \& Elsey, K. (1995) Chemical factors involved in selection of host plant for oviposition by the pickleworm moth (Lepidoptera: Pyralidae). Florida Entomologist, 78, 482-492.

Piñero, J.C. \& Dorn, S. (2007) Synergism between aromatic compounds and green leaf volatiles derived from the host plant underlies female attraction in oriental fruit moth. Entomologia Experimentalis et Applicata, 125, 185-194.

R Development CoreTeam (2006) R: A Language and Environment for Statistical Computing. R Foundation for Statistical Computing, Austria [WWW document]. URL http://www.R-project.org [accessed on 5 June 2007]. 
Ramaswamy, S.B. (1988) Host finding by moths: sensory modalities and behaviours. Journal of Insect Physiology, 34, 235-249.

Reddy, G., Tabone, E. \& Smith, M. (2004) Mediation of host selection and oviposition behavior in the diamondback moth Plutella xylostella and its predator Chrysoperla carnea by chemical cues from cole crops. Biological Control, 29, 270-277.

Renwick, J. \& Chew, F. (1994) Oviposition behavior in Lepidoptera. Annual Review of Entomology, 39, 377-400.

Rojas, J., Virgen, A. \& Cruz-López, L. (2003) Chemical and tactile cues influencing oviposition of a generalist moth, Spodoptera frugiperda (Lepidoptera: Noctuidae). Environmental Entomology, 32, 1386-1392.

Sidney, M., Brown, K., Judd, G. \& Gries, G. (2008) Stimuli affecting selection of oviposition sites by female peach twig borer, Anarsia lineatella Zeller (Lepidoptera: Gelechiidae). Journal of Applied Entomology, 132, 538-544.
Spencer, J.L., Pillay, S. \& Bernays, E.A. (1999) Synergism in the oviposition behavior of Plutella xylostella: sinigrin and wax compounds. Journal of Insect Behavior, 12, 483-500.

Tagawa, J., Matsushita, A. \& Watanabe, T. (2008) Leaf surface preference in the cabbage worm, Pieris rapae crucivora, and parasitism by the gregarious parasitoid Cotesia glomerata. Entomologia Experimentalis et Applicata, 129, 37-43.

Thompson, J. \& Pellmyr, O. (1991) Evolution of oviposition behavior and host preference in Lepidoptera. Annual Review of Entomology, 36, 65-89.

Visser, J. (1986) Host odor perception in phytophagous insects. Annual Review of Entomology, 31, 121-144.

Accepted 6 January 2010

First published online 25 February 2010 